\title{
Shear strength properties of water treatment residues
}

B. C. O'Kelly MEngSc, PhD, CEng, CEnv, MICE, FIEI, PGeo, MIGI, FGS and M. E. Quille BA, BAI, MIEI

This paper presents the physical, standard Proctor compaction and shear strength properties of alum water treatment residues derived from the production of potable water at municipal works. In particular, the effects of catchment geology, chemical treatments at the municipal works, hardening phenomena and shearing rate on the constitutive and shear strength responses of these high-plasticity organic clays were studied. Slurry residues have low bulk and dry densities $\left(0.96-I \cdot 13\right.$ and $0.21-0.36 \mathrm{t} / \mathrm{m}^{3}$ respectively) and low specific gravity of solids (1.83-I.99), and are highly compressible, although the consolidation rate is low. The dewatered residues have high values of effective angle of shearing resistance of $39-44^{\circ}$. Low concentrations of polyelectrolyte added to the residues altered the constitutive response (more elastic perfectly plastic, with shear failure occurring between $2 \%$ and $10 \%$ compressive strain): the undrained shear strength was enhanced by $10-20 \%$ and the effective angle of shearing resistance increased by $2^{\circ}$. Alum residues derived from peaty catchments were found to have marginally higher undrained shear strengths than those from a limestone-bedrock catchment.

Recommendations are made regarding adequate dewatering of the slurry residue and the efficient landfill disposal of the pressed residue cake.

\section{INTRODUCTION}

Water treatment residues (WTRs) are the slurry by-products derived from the filter backwash, water softening, chemical coagulation, flocculation and settling processes used in the treatment of potable water (Metcalf and Eddy, 2003; Twort et $a l ., 2000)$. The WTRs comprise sand, silt and clay particles, colloidal organic matter, and chemicals (coagulants, polyelectrolytes and conditioners) that are added to the source water during the treatment processes. Chemical coagulation using ferric chloride, or more generally using aluminium sulphate, causes the colloidal particles (i.e. less than $1 \mu \mathrm{m}$ in size) that are suspended in the source water entering the treatment plant to aggregate into flocs that settle out more readily under gravity. Polyelectrolytes are synthetic longchained organic molecules that act as binding agents, increasing the inherent shear strength of the newly formed flocs and hence the density and viscosity of the slurry residue (Chih Chao et al., 1997; Turchiuli and Fargues, 2004). Chemical conditioners including sulphuric acid, bentonite, calcium or sodium hydroxide, and sodium silicate may also be added, depending on the nature of the source water, in order to improve the polyelectrolyte performance. The residue is characterised as alum or iron WTR, depending on the coagulant type used.

Increasing quantities of WTRs are being produced worldwide annually owing to increasing demand for potable water and more stringent regulations: for example, the Drinking Water Directive (European Parliament and Council of the European Union, 1998). Currently, the principal disposal methods for WTRs are: storage, often over an infinite period, in sludge lagoons; or mass and volume reduction by mechanical or thermal means, followed by landfilling, either at dedicated monofills or co-disposal at municipal landfills. In a municipal landfill the WTR may be disposed of alone in dedicated depositional areas, or placed in thin layers and mixed and scarified in situ with municipal waste, which has the effect of reducing the bulk water content and increasing the shear strength of the wet WTR. However, the landfill route is subject to stringent controls, such as the Landfill and Waste Management Directives (European Parliament and Council of the European Union, 1999, 2006). Since 2006, landfill operators have not been able to accept sludge or residue material with a water content value greater than 300\%, which is set as an indirect, albeit sometimes unreliable, measure of the undrained shear strength necessary for efficient handling, trafficability and geotechnical stability of the landfill slopes. The water content $(w)$ is defined as the ratio of the mass of the pore water to the mass of the dry solids, expressed as a percentage. The mass of the dry solids is measured after ovendrying the test specimen at $105 \pm 5^{\circ} \mathrm{C}$ for a period of $24 \mathrm{~h}$.

Table 1 lists some engineering properties of alum WTRs reported in the literature (Lim et al., 2002; Novak and Calkins, 1975; 0'Kelly, 2008b; O'Kelly and Quille, 2009; Raghu and Hsieh, 1986; Roque and Carvalho, 2006; Wang and Tseng, 1993; Wang et al., 1992). In general, alum WTRs have very high liquid and plastic limit values, a relatively low specific gravity of solids value of $1 \cdot 8-2 \cdot 2$, a high loss in dry mass on ignition (LOI) value of up to $60 \%$; and the wet residues have low bulk density values of $1 \cdot 0-1 \cdot 2 \mathrm{t} / \mathrm{m}^{3}$. The high plasticity is due to the exceptionally high affinity of the alum coagulant for the pore water, the destabilisation of the dispersed solids during the coagulation process (Wang et al., 1992), and the high organic content (reflected by the high LOI values). 


\begin{tabular}{|cc|}
\hline Parameter & Value \\
\hline Liquid limit: \% & $100-550$ \\
Plastic limit: \% & $80-325$ \\
Specific gravity of solids & $1 \cdot 8-2 \cdot 2$ \\
Loss in dry mass on ignition: \% & $10-60$ \\
Bulk density: $\mathrm{t} / \mathrm{m}^{3}$ & $1 \cdot 0-1 \cdot 2$ \\
Dry density: $\mathrm{t} / \mathrm{m}^{3}$ & $0 \cdot 12-0 \cdot 36$ \\
Effective cohesion: $\mathrm{kPa}$ & 0 \\
Effective angle of shearing resistance: degrees & $28-44$
\end{tabular}

Table I. Typical engineering properties of alum WTRs

Figure 1 shows undrained shear strength against water content data determined using the fall-cone penetrometer (Wang et al., 1992), miniature laboratory vane (Novak and Calkins, 1975; Wichmann and Riehl, 1997) and triaxial compression (O'Kelly, 2006) apparatus for alum and iron WTRs, as well as municipal sewage sludge, the latter a by-product of wastewater treatment processes. The geoengineering properties of sewage sludge are similar in many respects to those of WTRs, and extensive research on the shear strength behaviour of sewage sludge has been reported by 0'Kelly (2004, 2005a, 2005b, 2005c, 2006). However, sewage sludge is bioactive, and usually at moderate to strong levels of biodegradation, whereas WTRs are relatively inert.

There is a significant variation in the undrained shear strength at a given water content value for the test materials presented in Figure 1, which is expected, owing to the natural variability of the source waters and hence the mineralogy and organic content of the suspended solids. Different types and levels of chemical treatment and, in the case of the sewage sludges, biological treatments had also been used to separate the residue by-product at the municipal works. A comparison of the undrained shear strength data indicates that alum WTR tends to have marginally higher shear strength values than iron WTR, and that both alum and iron WTRs generally have higher undrained shear strengths than municipal sewage sludges.

In addition, Wang et al. (1992) have reported that wet alum WTR is thixotropic, with strength gains (ratio of the undrained shear strength measured after a specified curing period to the remoulded shear strength under constant external conditions and specimen composition) of 5.7-8.0 over a water content range of $430 \%-810 \%$ respectively (liquidity index $I_{\mathrm{L}}=1 \cdot 6-$ $2 \cdot 0)$. Thixotropic effects are generally most significant in remoulded soils with a high liquidity index. The effective angle of shearing resistance $\left(\phi^{\prime}\right)$ values of $28-44^{\circ}$ reported for alum WTRs are high compared with the values generally associated with high-plasticity organic clays (for example montmorillonite, with $\phi^{\prime}=5-10^{\circ}$ : Mitchell and Soga, 2005). Alum WTRs are highly compressible, with $C_{\mathrm{c}}=2 \cdot 1-3 \cdot 1$ and $C_{\mathrm{sec}}=0 \cdot 005-0 \cdot 010$ (where $C_{\mathrm{c}}$ is the primary compression index, and $C_{\mathrm{sec}}$ is the coefficient of secondary compression, defined as the volumetric strain corresponding to a tenfold increase in elapsed time following the primary consolidation phase) reported from oedometer tests by 0'Kelly and Quille (2009). However, alum WTRs have a very low hydraulic conductivity (coefficient of permeability $k=10^{-9}-10^{-11} \mathrm{~m} / \mathrm{s}$ ), owing to the nature of the floc microstructure, the high organic content, and alum's exceptionally high affinity for the pore water.

The aims of this paper are to study the physical, compaction and shear strength properties of alum WTRs derived from different catchments, and in particular to study the effects of several influencing factors: catchment geology; chemical additives; shearing rate; and hardening phenomena. In addition, recommendations are made regarding the efficient dewatering and landfill disposal of alum WTRs.

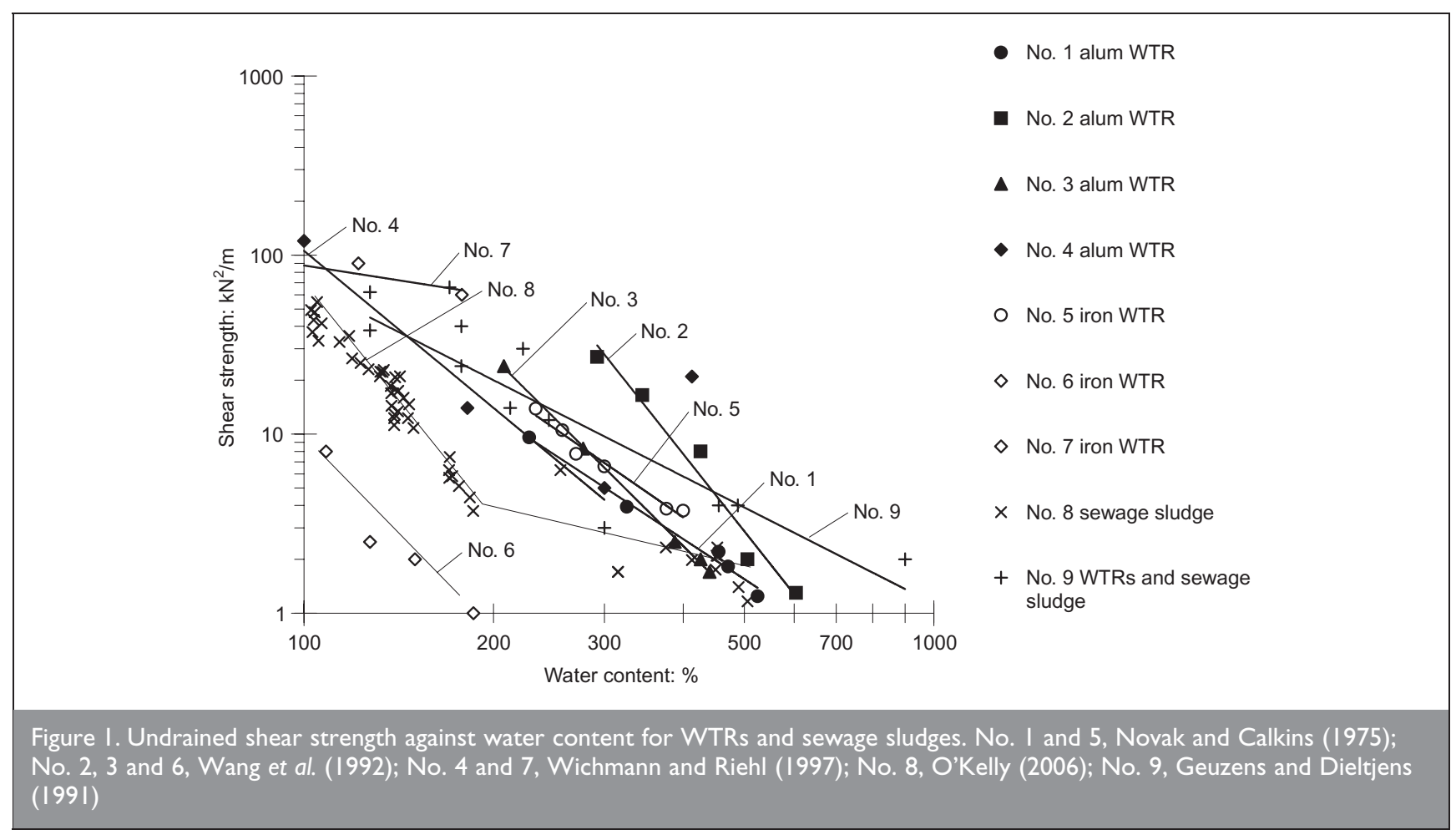




\section{TEST MATERIALS}

Alum WTRs were sourced from three of the larger municipal water treatment plants in Ireland: the Ballymore Eustace and Leixlip works in County Kildare, and the Clareville works in County Limerick. Together, these plants account for almost $30 \%$ of the annual production of potable water in Ireland. The raw water entering the treatment plants is sourced from three different catchments, thereby providing a good overall representation of the alum WTRs produced in the country. The residues had been coagulated using Chemifloc $4140^{\circledR}$ alum and conditioned using Magnafloc LT25 ${ }^{\circledR}$ polyelectrolyte, and the combined dosages that had been added during the different treatment processes are listed in Table 2. These dosages are at the higher end of the ranges normally used in practice, since the source waters were all medium high in turbidity.

\section{I. Sample WTR I}

The residue from the Ballymore Eustace works (WTR 1) was a brownish-green material derived from the treatment of medium-colour, medium-turbidity raw water that had been sourced from the Dublin and Wicklow mountains (upland catchment of peat over granite bedrock) and stored prior to treatment in Poulaphouca reservoir, County Wicklow. The slurry residue had been dewatered using a recessed-plate filter press device (applied stress of $1500 \mathrm{kPa}$ ), with about $1200 \mathrm{t}$ of wet WTR $\left(w=340 \% ; I_{\mathrm{L}}=0 \cdot 4\right)$ produced at the treatment works in 2007. Samples of the pressed residue cake were obtained from the skip containers at the end of the dewatering process at the treatment works in November 2005.

\subsection{Sample WTR 2a}

The residue from the Clareville works (WTR 2a) was a brownish-green material derived from the treatment of highcolour, high-turbidity raw water that had been sourced from the river Shannon (lowland catchment of peat over limestone bedrock). A higher alum dosage of 60-100 mg/l source water

\begin{tabular}{|lcccc|}
\hline Chemical additive & WTR I & WTR 2a & WTR 2b & WTR 3 \\
\hline Alum: $\mathrm{mg} / \mathrm{l}$ & $40-65$ & $60-100$ & 0 & $40-60$ \\
Polyelectrolyte: $\mathrm{mg} / \mathrm{l}$ & $0.6-\mathrm{I} \cdot 5$ & $0.8-2.0$ & 0 & $0.2-1.0$ \\
Dry $\mathrm{H}_{2} \mathrm{SO}_{4}: \mathrm{kg} / \mathrm{day}$ & 0 & 0.5 & 0 & 0 \\
& & & & \\
\hline & & & \\
Table 2. Chemicals added during treatment processes.
\end{tabular}

was required on account of the high turbidity, and sulphuric acid was also added to adjust the $\mathrm{pH}$ in order to improve the coagulant performance. The slurry residue was dewatered using a mechanical belt-press device (applied stress of $800-$ $1000 \mathrm{kPa}$ ), and the pressed material was then allowed to airdry naturally in shallow drying beds, with about $900 \mathrm{t}$ of wet WTR ( $w=570 \% ; I_{\mathrm{L}} \cong 1 \cdot 1$ ) produced at the treatment works in 2006. Residue samples were obtained from the drying beds in October 2006.

\subsection{Sample WTR 2b}

Material WTR 2b was the slurry residue sourced directly after the initial screening process at the Clareville works (i.e. before any chemical treatments). A column of this thickened suspension was allowed to settle out naturally and dry by evaporation at ambient laboratory temperature of $20^{\circ} \mathrm{C}$. Residue WTR 2b was obtained from the treatment works in February 2008 with the aim of studying the effect of the chemical additives on the constitutive and shear strength behaviours.

\subsection{Sample WTR 3}

The residue from the Leixlip works (WTR 3) was a dark brown material derived from the treatment of medium-colour, medium-turbidity raw water that had been sourced from the river Liffey (upland catchment of limestone bedrock). The residue had been dewatered using a recessed-plate filter press device (applied stress of $1500 \mathrm{kPa}$ ), with about $1100 \mathrm{t}$ of wet WTR ( $\left.w=300 \% ; I_{\mathrm{L}} \cong 0.4\right)$ produced at the treatment plant in 2007. Samples of the residue cake were obtained from the skip containers at the end of the dewatering process in November 2006.

\section{INDEX AND PHYSICAL PROPERTIES}

The WTR samples were stored in the geotechnical laboratory in separate 70 litre plastic drums (fitted with covers, but not hermetically sealed) at ambient temperature. Table 3 lists the index and physical properties determined using standard geotechnical laboratory tests in accordance with BS 1377 (BSI, 1990a) on fresh residue specimens obtained directly from the treatment works.

In general, the mechanically dewatered WTRs still had very high values of water content (300-570\%) and void ratio (5.7$11 \cdot 3$ ), with low bulk and dry density values of $1 \cdot 06-1 \cdot 10 \mathrm{t} / \mathrm{m}^{3}$ and $0 \cdot 18-0 \cdot 26 \mathrm{t} / \mathrm{m}^{3}$ respectively. The wide range of water

\begin{tabular}{|lcccc|}
\hline Parameter & WTR I & WTR 2a & WTR 2b & WTR 3 \\
\hline Water content: \% & 340 & 570 & 700 & 300 \\
Liquid limit: \% & 490 & 550 & 550 & 430 \\
Plastic limit: \% & 240 & 260 & 280 & 220 \\
Plasticity index & 250 & 290 & 270 & 210 \\
Specific gravity of solids & 1.86 & 1.99 & 1.83 & 1.90 \\
Loss in dry mass on ignition: \% & 57 & 45 & 41 & 46 \\
Bulk density: $t / \mathrm{m}^{3}$ & 1.08 & 1.06 & 1.04 & 1.10 \\
Dry density: t/m & 0.25 & 0.18 & 0.14 & 0.26 \\
Void ratio & 6.3 & 11.3 & 14.6 & 5.7 \\
Adhesion limit: \% & 240 & 365 & 355 & 345 \\
& \multicolumn{5}{c}{} \\
\hline Table 3. Properties of WTRs directly from treatment works. & \\
\hline
\end{tabular}


content and hence void ratio values was due mainly to the different confining pressures that had been applied by the different dewatering systems and, to a lesser extent, to differences in the hydraulic conductivity of these materials. WTR 2a and WTR 2b were of slurry consistency (water content values greater than the liquid limit condition), whereas WTR 1 and WTR 3 were soft to firm in consistency, owing to the greater level of dewatering that had been achieved under the higher confining pressure of $1500 \mathrm{kPa}$ applied by the recessplate filter press device.

The WTRs had very high values of liquid limit (430-550\%) and plasticity index $\left(I_{\mathrm{p}}=210-290\right)$, and the adhesion limit (determined as the lowest water content at which the solids adhered to a clean dry spatula) was also very high - in excess of $240 \%$ water content. These values correspond to fresh specimens direct from the treatment works. The Atterberg limit values of the bulk samples, which were stored without disturbance in the plastic drums, were found to change over time. For example, the plastic limit value of WTR 3 specimens taken from the upper layer in the plastic drum was found to increase from $220 \%$ to $325 \%$ over an 18month period. X-ray diffraction (XRD) analysis indicated that the crystalline fraction of the WTRs comprised quartz and manganoan calcite - both common bedrock minerals that are present as colloidal particles in the source waters. The chemical additives did not feature in the XRD analysis, since the alum was present in its amorphous aluminium hydroxide form, and the polyelectrolytes are organic molecules. The high values of loss in dry mass on ignition (LOI) of 41-57\% were determined by igniting dry powdered test specimens at a temperature of $440^{\circ} \mathrm{C}$ in a muffle furnace, which oxidises the organic solids and polyelectrolytes. The polyelectrolytes, which are unstable above $150^{\circ} \mathrm{C}$, comprised typically $3 \cdot 3 \%$ dry solids mass (range 1.6-4.8\% dry solids mass for WTR 1 , WTR 2a and WTR 3). Nevertheless, the LOI value is a good reflection of the organic content, since the crystalline fraction remains stable at the ignition temperature of $440^{\circ} \mathrm{C}$. Hence the WTRs are classified as high-plasticity organic clay. The specific gravity of solids values of $1.83-1.99$, which were measured using the small pyknometer method, were relatively low, and consistent with the high organic content.

The water content of the wet residue samples was reduced over time in the geotechnical laboratory by allowing thin layers of the wet material to air-dry naturally in trays at ambient temperature. Overall, the wet WTRs dried slowly, owing to the exceptionally high affinity of the alum for the pore water (Wang et al., 1992), the very low hydraulic conductivity (O'Kelly and Quille, 2009; Wang and Tseng, 1993), and the high organic content.

\section{COMPACTION}

Standard Proctor compaction tests were conducted on wet WTR samples that had been allowed to air-dry naturally over different periods in the geotechnical laboratory, thereby achieving a range of water contents. The residue was regularly mixed during the air-drying process, and any clumps were disaggregated to pass the $20 \mathrm{~mm}$ sieve size prior to standard Proctor compaction testing using the 1 litre compaction mould. Sets of three cylindrical subspecimens (each initially $38 \mathrm{~mm}$ in diameter and $76 \mathrm{~mm}$ high) were prepared from the standard
Proctor compacted specimens. The mass, volume and water content values were determined after these subspecimens had been allowed to slowly air-dry further, and shrink without cracking, at ambient laboratory temperature.

Figure 2(a) shows the density values achieved by standard Proctor compaction. Similar compaction relationships were obtained for the three WTRs, with the dry density increasing from 0.21 to $0.36 \mathrm{t} / \mathrm{m}^{3}$ with reducing water content from $400 \%$ to $200 \%$. The bulk density $\left(0 \cdot 96-1 \cdot 13 \mathrm{t} / \mathrm{m}^{3}\right)$ and dry density values were very low, although in line with the high water content and low specific gravity of solids values. The optimum water content to achieve the maximum dry density for standard Proctor compaction did not occur within the water content range tested, although this trend in the dry density data is consistent with Wang et al. (1992). An effect of coagulating and flocculating a soil is the reduction of its optimum water content for compaction.

Figure 2(b) shows the density values achieved by allowing the subspecimens that had been prepared from the standard Proctor compacted specimens to stand and air-dry naturally further. Below 200\% water content, the bulk and dry density values of the air-dried specimens were consistently higher than those achieved by standard Proctor compaction alone. Controlled drying and volumetric shrinkage without cracking of the wet subspecimens produced lower air void values ( $a=$ $2 \cdot 5-3 \%$ ), compared with those achieved by standard Proctor compaction alone of the dried residue $(a=3 \cdot 5-5 \%)$. The WTRs were brittle, and the material crushed to a dust under the impact of the compaction hammer below 160\% water content.

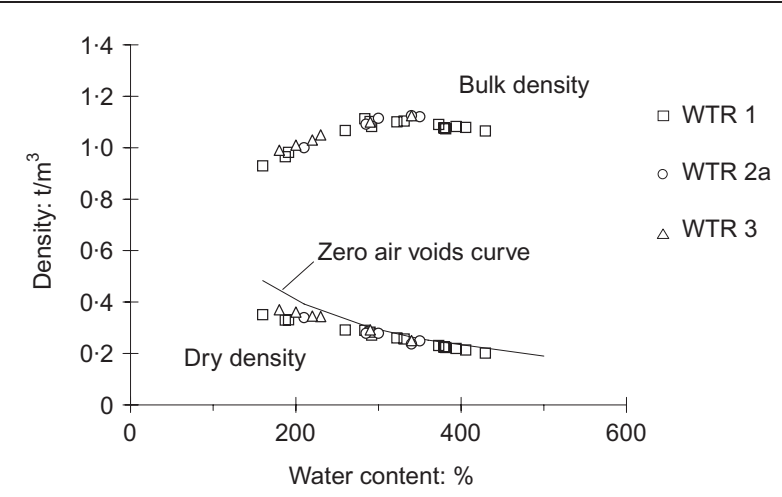

(a)

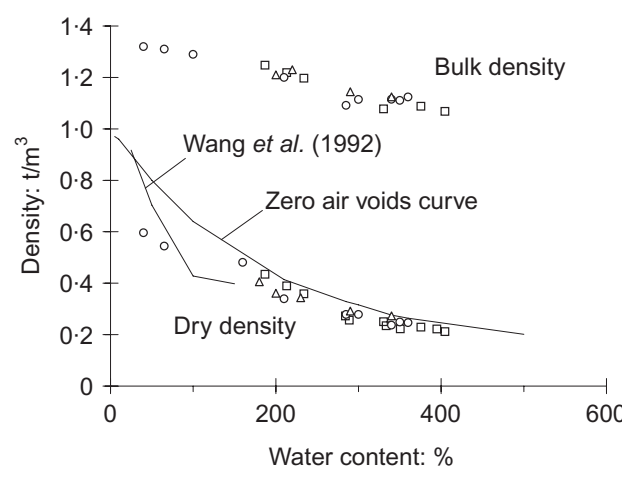

$\square$ WTR 1 - WTR $2 a$ $\triangle$ WTR 3

(b)

Figure 2. Standard Proctor compaction: (a) compaction alone; (b) compaction followed by natural air-drying 


\section{SHEAR STRENGTH}

\section{I. Undrained shear strength}

Unconsolidated undrained (UU) triaxial compression tests were conducted on the partially saturated specimens (initially $38 \mathrm{~mm}$ in diameter and $76 \mathrm{~mm}$ high) that had been prepared from the standard Proctor-compacted samples, and which were allowed to air-dry slowly further at ambient laboratory temperature in order to achieve a range of water content values. A cell confining pressure of $100 \mathrm{kPa}$ was applied to the triaxial specimens, which were then sheared quickly at $2 \%$ axial strain/ min. The standard correction for the restraining effect of the enclosing rubber membrane on the barrelling specimendeformation response was applied to the measured deviator stress value (BS 1377: BSI, 1990b). Specimen failure was deemed to have occurred at a limiting $20 \%$ axial strain unless the deviator stress value had reached a peak at a lower strain value.

\subsection{Thixotropic and shearing rate effects}

Laboratory vane and UU triaxial compression tests were carried out on specimens of residue WTR 2a that had been allowed to cure, undisturbed at a constant composition, over different time periods near the liquid and plastic limit conditions respectively.

5.2.1. Laboratory vane. Saturated, fresh WTR 2a material with a water content marginally below the liquid limit condition $\left(I_{\mathrm{L}}\right.$ $\cong 0.90$ ) was pressed into specimen moulds (70 $\mathrm{mm}$ square in plan and $70 \mathrm{~mm}$ high), taking care to avoid the entrapment of air voids. These specimens were hermetically sealed by wrapping in cling film and allowed to stand at ambient laboratory temperature. The undrained shear strength was measured using the laboratory vane apparatus after the specimens had been allowed to cure over time periods of up to four weeks. The specimens were sheared quickly using a cruciform vane (25 $\mathrm{mm}$ in both width and length) and an angular rotation of $0 \cdot 1 \mathrm{rev} / \mathrm{min}$.

\subsubsection{Triaxial compression. Four identical, normally} consolidated triaxial specimens A-D, each $38 \mathrm{~mm}$ in diameter and $76 \mathrm{~mm}$ high, were prepared from a saturated cake of residue WTR 2a that had been pressed to a water content marginally above its plastic limit value $\left(I_{\mathrm{L}} \cong 0 \cdot 14\right)$ in order to study the effects of different curing periods and shearing rates on the shear strength behaviour. The residue cake had been prepared using a consolidometer press developed by 0'Kelly (2008a, 2009) in which a slurry specimen, $152 \mathrm{~mm}$ in diameter and $165 \mathrm{~mm}$ high, was allowed to consolidate under applied stresses of 7·5, 15, 30 and $60 \mathrm{kPa}$ (each load stage of 7 days in duration) and with two-way specimen drainage to atmosphere. Triaxial specimens A, B and C were allowed to cure, undisturbed, for periods of 0,5 and 12 days.

A cell confining pressure of $260 \mathrm{kPa}$ was applied to the saturated triaxial specimens (Skempton pore pressure coefficient $B>0.98$ ) during these unconsolidated undrained compression tests. Specimens A, B and C were sheared slowly at $3 \cdot 3 \times 10^{-5} \%$ strain/min in order to allow full equilibration of the pore water pressures to occur throughout the specimens at failure. The fourth specimen, D, was not allowed to cure, and was also sheared at a much quicker rate of $2 \%$ axial strain/min.

\subsection{Effective stress shear strength properties}

Sets of four identical and normally consolidated triaxial specimens were also prepared from saturated cakes of the different WTRs that had been pressed and allowed to equilibrate under applied vertical stresses of 10, 16 and $30 \mathrm{kPa}$ in the consolidometer apparatus.

The effective stress shear strength properties were determined using isotropic consolidated-undrained (ICU) triaxial compression tests, and with continuous measurement of the pore water pressure response. Effective cell confining pressures of $\boldsymbol{\sigma}_{\mathrm{c}}^{\prime}=30,60,120$ and $150 \mathrm{kPa}$ were applied to each set of specimens, which were allowed to drain radially and from both ends over a $24 \mathrm{~h}$ period, and with continuous measurement of the volume of pore water expelled against a back pressure of $200 \mathrm{kPa}$. The shearing rates of the order of $10^{-5} \%$ strain $/ \mathrm{min}$, which allowed full equilibration of the pore water pressures to occur throughout the specimens at failure, were determined using standard curve-fitting analysis (BS 1377: BSI, 1990c) of the data from the triaxial consolidation data.

\section{SHEAR STRENGTH RESULTS AND ANALYSIS}

\section{I. Undrained shear strength}

Figure 3 shows data for deviator stress against axial strain from the UU triaxial compression tests for the water content range $185-295 \%$. Specimens in the plastic state usually underwent a barrelling deformation response, with failure generally deemed to have occurred for the limiting 20\% strain criterion. However, unlike most organic clays (Bell, 2000), the stiff and very stiff specimens achieved peak deviator stress values at comparatively low axial strains of $5-10 \%$.

Figure 4 shows the data for undrained shear strength $\left(\boldsymbol{s}_{\mathrm{u}}\right)$ against water content on a logarithm-logarithm plot. Overall, similar undrained shear strength relationships were obtained for WTR 1, WTR 2a and WTR 2b (derived from peaty catchments) over the water content range tested. The undrained shear strength of WTR 3 (derived from limestone catchment) was only marginally lower; consistent with its relatively lower plasticity index value (Table 3), which is related to the different catchment geology/mineralogy.

\subsection{Thixotropic and shearing rate effects}

Figure 5(a) shows the significant effects of thixotropic hardening for the WTR 2a specimens that had been allowed to cure, undrained and at a constant composition, marginally below the liquid limit condition $\left(I_{\mathrm{L}}=0.90\right)$. The vane shear strength was found to increase from initially $3 \mathrm{kPa}$ to about $7 \mathrm{kPa}$ after a nine-day curing period and with a strength gain ratio of 3.3 achieved by the end of the four-week test period. The higher strength gain ratios of 5.7-8.0 reported for alum WTRs by Wang et al. (1992) corresponded to higher liquidity index values of $1 \cdot 6-2 \cdot 0$, which is in line with the expected trend of increasing thixotropy with increasing liquidity index.

Figure 5(b) shows the data for deviator stress against axial strain for the saturated, triaxial specimens A-D of residue WTR 2a. Similar constitutive responses and shear strength values were measured for specimens A, B and C (sheared slowly at the same strain rate but after different curing periods of 0,5 and 12 days), indicating negligible thixotropic strength gain over 

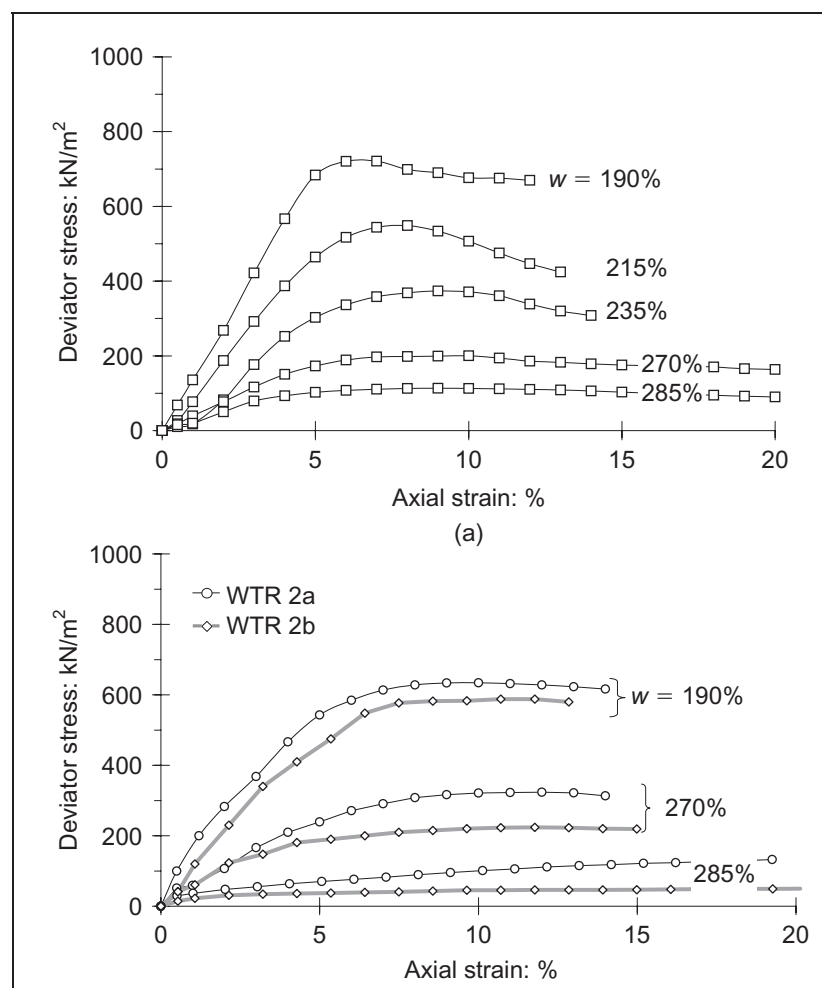

(b)

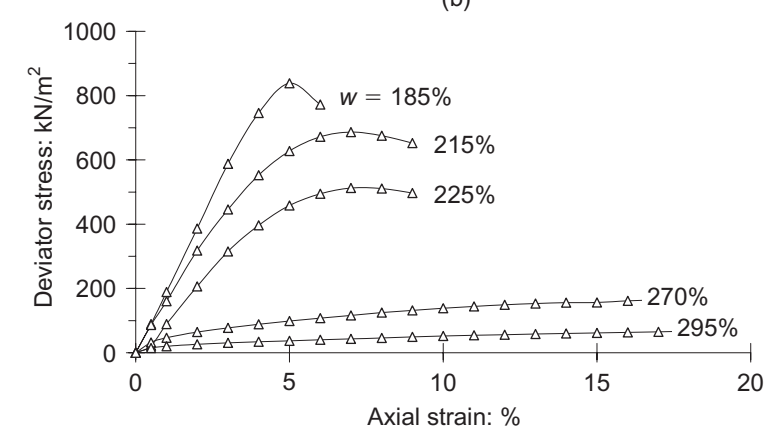

(c)

Figure 3. Deviator stress-strain data from UU triaxial compression tests: (a) WTR I; (b) WTR 2a and WTR 2b; (c) WTR 3

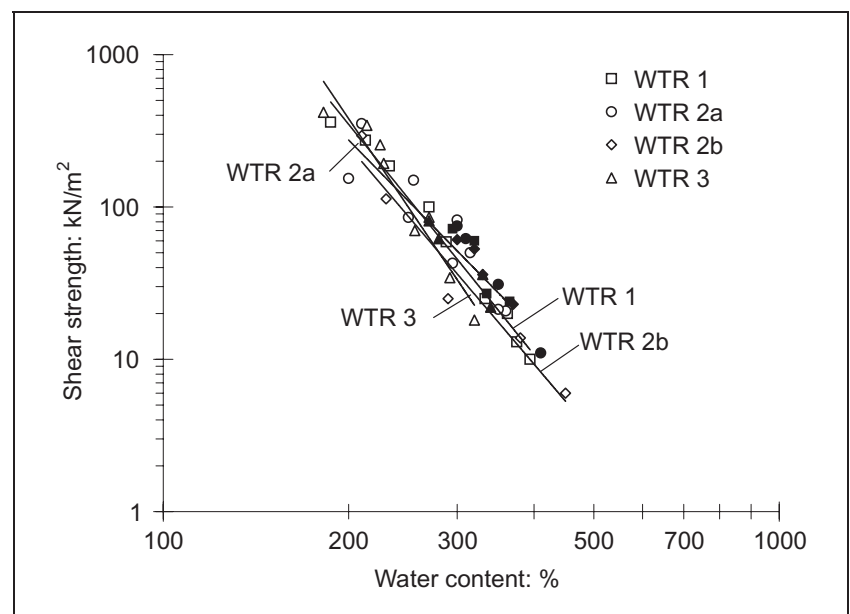

Figure 4. Undrained shear strength against water content. Hollow symbols denote UU triaxial compression; solid symbols denote ICU triaxial compression

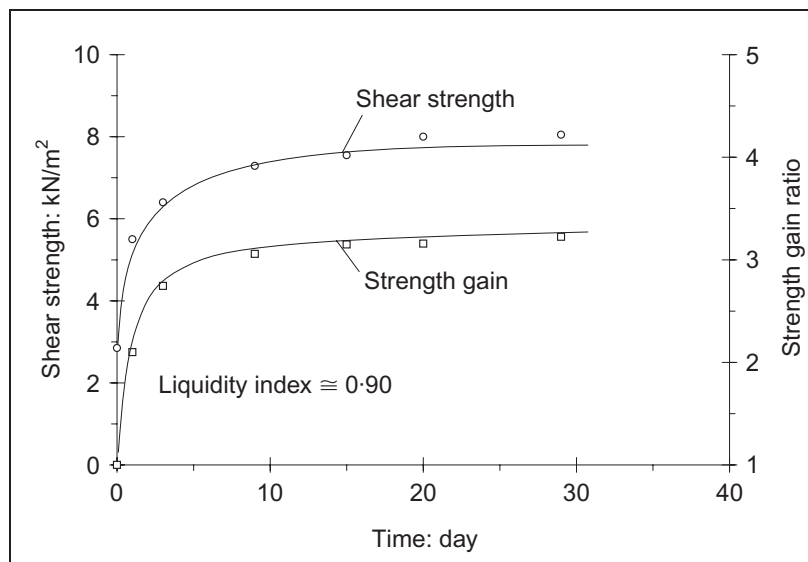

(a)

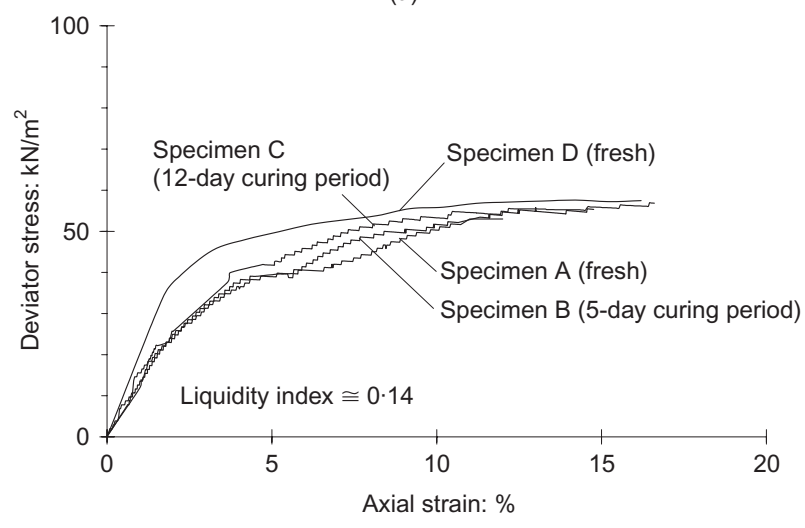

(b)

Figure 5. Thixotropic and shearing rate effects for residue WTR 2a: (a) laboratory vane data; (b) undrained triaxial compression data. Specimens A-C sheared slowly; specimen D sheared quickly

the 12-day test period, which was expected, since the specimen water content was near the plastic limit condition $\left(I_{\mathrm{L}} \cong 0 \cdot 14\right)$. Seed and Chan (1959) reported that the level of thixotropic hardening decreases with decreasing liquidity index, and that the plastic limit represents a lower bound for thixotropic behaviour. The effect of the shearing rate can be considered by comparing the constitutive responses of the fresh, identical specimens A and D in Figure 5(b). As expected, specimen D experienced a much stiffer response, since this specimen had been sheared quickly at a strain rate five orders of magnitude greater than that used in testing specimen A. However, both specimens had similar undrained shear strengths, which suggests that undrained creep effects were not significant.

\subsection{Effective stress shear strength properties}

6.3.1. Consolidation stage. Figure 6 shows the isotropic consolidation data plotted as volumetric strain against logarithm of elapsed time. The three WTRs were highly compressible, with very large volumetric strains of $18-33 \%$ achieved by the end of the consolidation stage at $\boldsymbol{\sigma}_{\mathrm{c}}^{\prime}=$ $150 \mathrm{kPa}$. As expected, the WTR 1 and WTR $2 \mathrm{~b}$ specimens consolidated greater, owing to their higher LOI and initial void ratio values (Tables 3 and 4). Figure 7(a) shows the data in the traditional form of void ratio against logarithm of effective confining stress, and these single-increment consolidation data are also plotted as volumetric strain against effective stress in Figure 7(b). 


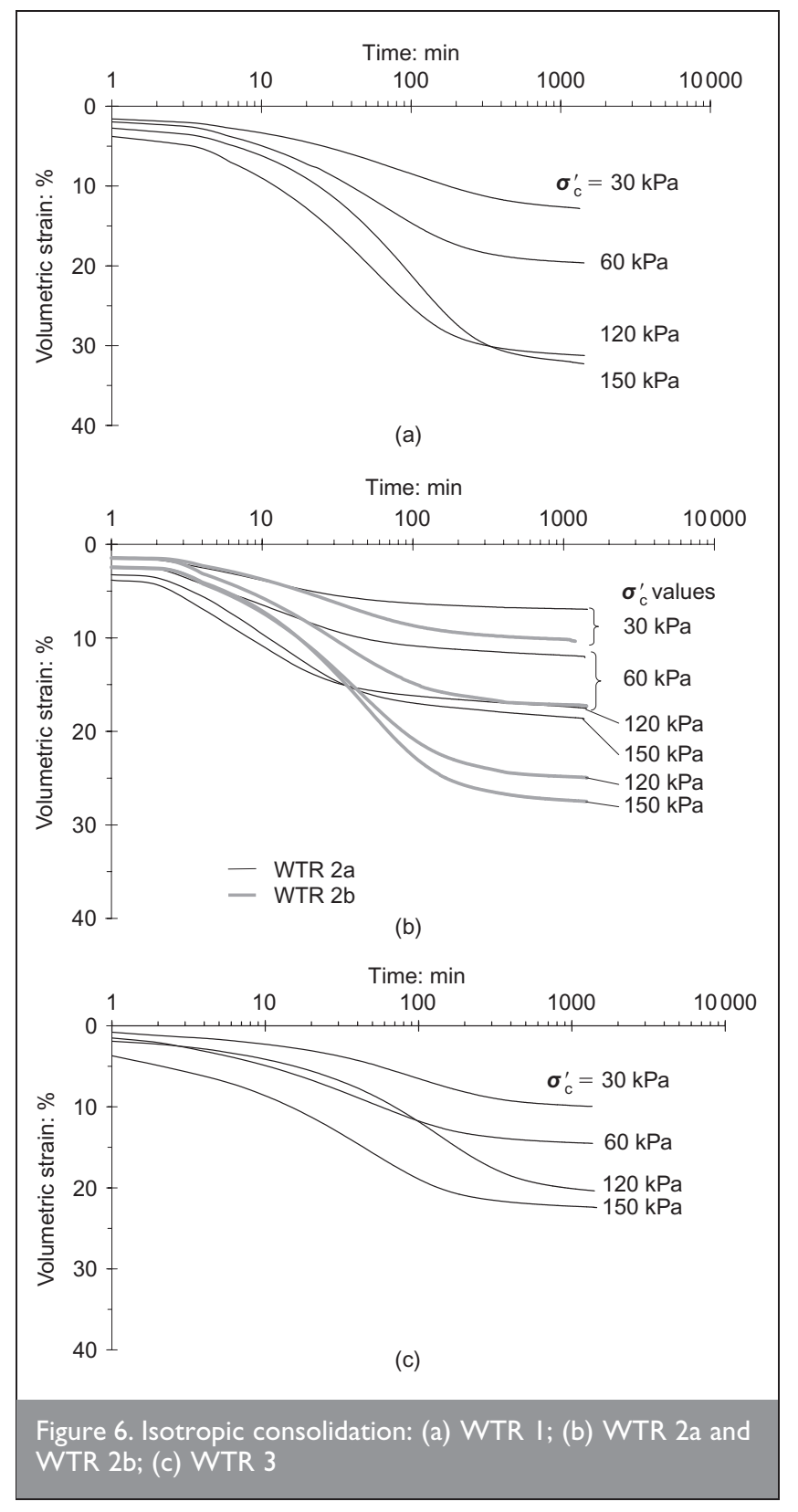

Figure 8 shows the coefficient of primary consolidation $\left(c_{\mathrm{vi}}\right)$ values determined from the isotropic consolidation plots in Figure 6 using a standard curve-fitting technique (BS 1377: BSI, 1990c), with the $c_{\mathrm{vi}}$ data for the three WTRs in general agreement and increasing from 0.08 to $0 \cdot 25 \mathrm{~m}^{2} /$ year for $\boldsymbol{\sigma}_{\mathrm{c}}^{\prime}=$ $30-150 \mathrm{kPa}$. A similar trend sequence and range of coefficient of primary consolidation values $\left(0 \cdot 1-0 \cdot 4 \mathrm{~m}^{2} /\right.$ year) were reported by 0'Kelly and Quille (2009) from oedometer tests on these WTRs over the effective stress range of 6-200 kPa.

\subsubsection{Shearing stage. The sets of triaxial specimens were} sheared slowly and in an undrained condition at rates of 3.3$6.0 \times 10^{-5} \%$ axial strain/min in order to allow full equalisation of the pore water pressures to occur throughout the specimens at failure. Figure 9 shows the deviator stress and pore water pressure responses against axial strain, as well as the $s^{\prime}-t^{\prime}$ effective stress path plots, where $s^{\prime}=\frac{1}{2}\left(\boldsymbol{\sigma}_{1}^{\prime}+\boldsymbol{\sigma}_{3}^{\prime}\right)$ and $t^{\prime}=\frac{1}{2}\left(\boldsymbol{\sigma}_{1}^{\prime}-\boldsymbol{\sigma}_{3}^{\prime}\right)$ are the MIT stress path parameters, and $\boldsymbol{\sigma}_{1}^{\prime}$ and $\boldsymbol{\sigma}_{3}^{\prime}$ are the major and minor effective principal stresses respectively. The $s^{\prime}-t^{\prime}$ data from the ICU triaxial compression

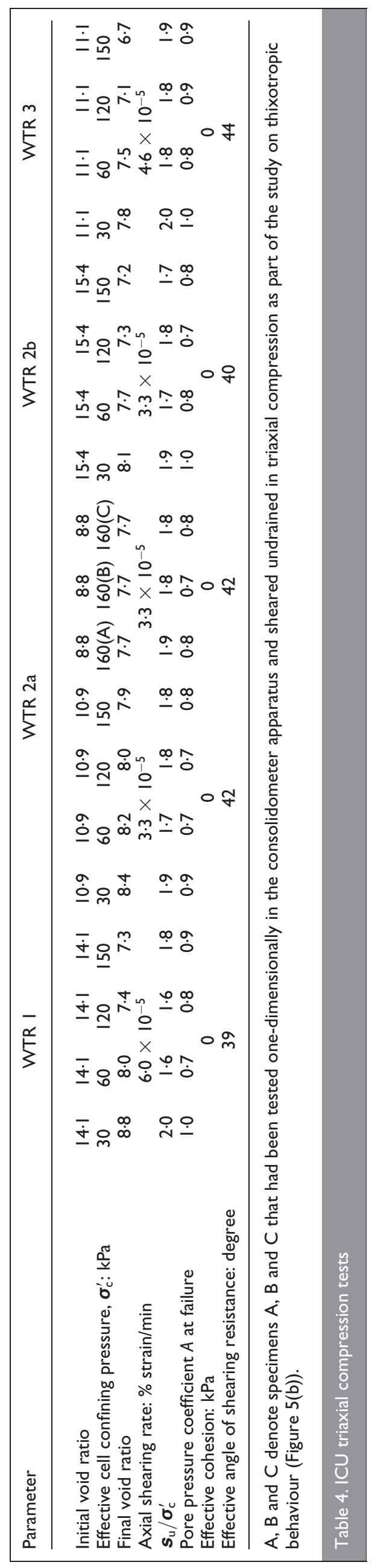




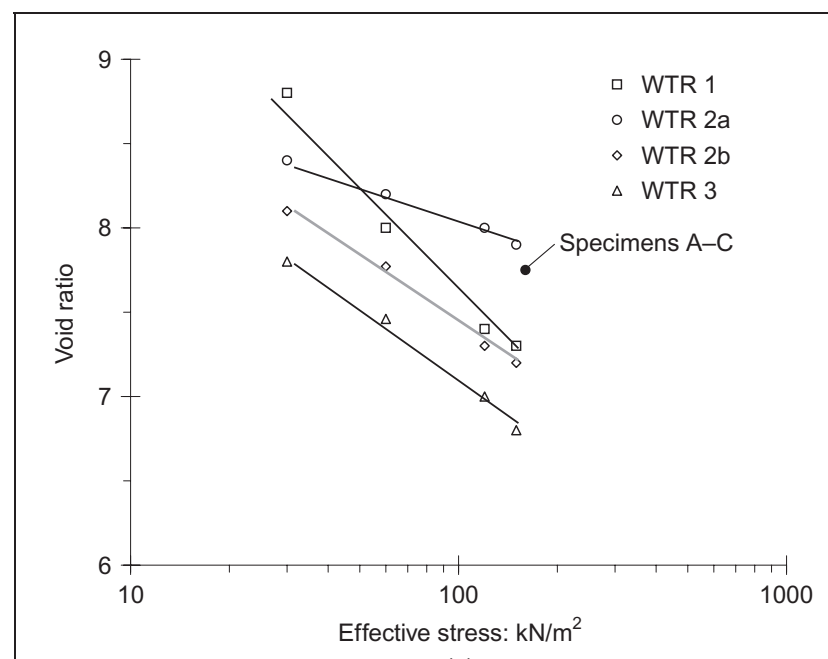

(a)

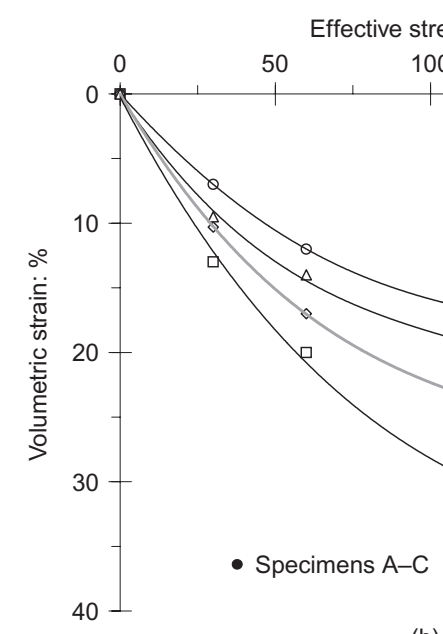

(b)

Figure 7. Isotropic consolidation: (a) void ratio against effective stress; (b) volumetric strain against effective stress. Specimens A-C were pressed one-dimensionally in the consolidometer apparatus

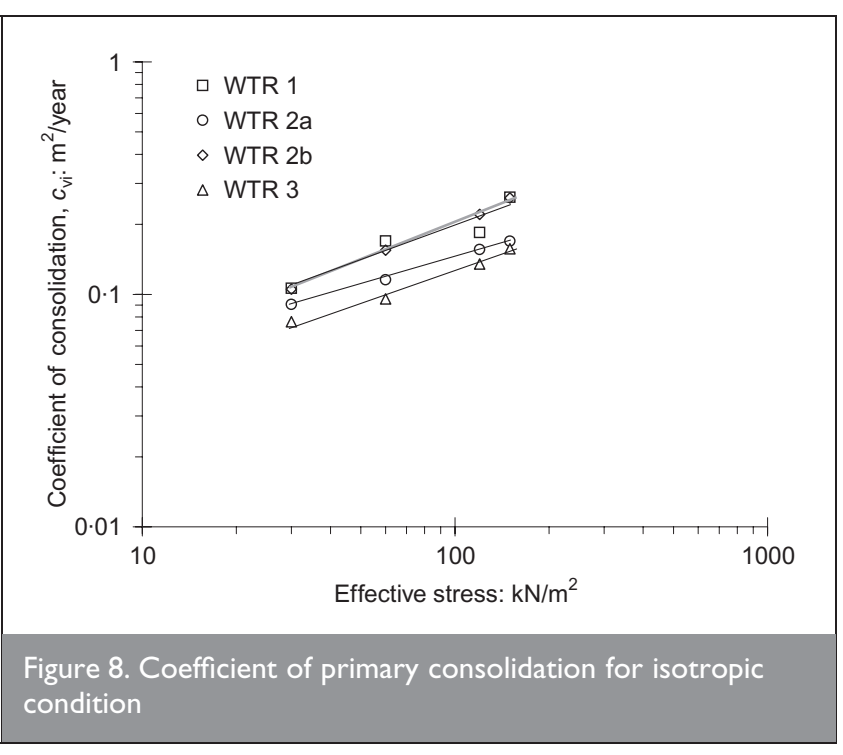

tests on WTR 2a specimens A, B and C (Section 5.2.2) are also included in Figure 9(b).

Specimen failure typically occurred between $2 \%$ and $10 \%$ axial strain (significantly below the limiting 20\% strain criterion more generally associated with shear failure of high-plasticity organic clays), and it is postulated that this more elastic perfectly plastic constitutive response may be due to the chemical additives in the WTRs (0'Kelly, 2008b). The standard corrections for the restraining effects of the filter-paper side drain and the enclosing rubber membrane on the barrelling specimen-deformation response were applied to the measured deviator stress values (BS 1377: BSI, 1990c).

The failure lines of best fit on the $s^{\prime}-t^{\prime}$ plots were drawn passing through the origin (i.e. effective cohesion of zero for these normally consolidated specimens) and aligned with the stress points corresponding to specimen failure. The effective stress paths at failure for the WTR 2a specimens A-C, which had an identical composition $\left(I_{\mathrm{L}}=0 \cdot 14\right)$ and were sheared at the same strain rate but after different curing periods of 0,5 and 12 days (Figure 9(b)), were also coincident with the WTR 2a failure line - further evidence of negligible thixotropic hardening occurring at low liquidity index values.

High values of effective angle of shearing resistance $\phi^{\prime}=39^{\circ}$, $42^{\circ}$ and $44^{\circ}$ were calculated from the gradient of the failure lines for WTRs 1, 2a and 3 in the $s^{\prime}-t^{\prime}$ plots. Similar $\phi^{\prime}$ values have been reported for alum WTRs $\left(\phi^{\prime}=42-44^{\circ}\right.$ : Wang et al., 1992) and other high-plasticity waste materials (e.g. sewage sludge with $\phi^{\prime}=32-37^{\circ}$ for LOI $=70-50 \%$ respectively: 0'Kelly, 2005b). The ratio of the shear strength $\left(\boldsymbol{s}_{\mathrm{u}}\right)$ to the effective confining pressure $\left(\boldsymbol{\sigma}_{\mathrm{c}}^{\prime}\right)$ for the WTRs in this study ranged between $1 \cdot 6$ and $2 \cdot 0$, with a mean $\boldsymbol{s}_{\mathrm{u}} / \boldsymbol{\sigma}_{\mathrm{c}}^{\prime}=1 \cdot 8$. The Skempton pore pressure coefficient $A$ value at specimen failure of $0 \cdot 7-1 \cdot 0$, with a mean value of $0 \cdot 8$, was consistent with normally consolidated behaviour and reported $A$ values at failure of 0.7-0.8 for alum WTRs (0'Kelly, 2008b; Wang et al., 1992).

Note that although the saturated ICU triaxial specimens had been sheared considerably slower (by typically five orders of magnitude), nevertheless the shear strength values determined for the ICU triaxial compression specimens were marginally greater than those determined for the partially saturated UU triaxial compression specimens (Figure 4). The main reason for the higher shear strength values was that the specimen preparation method for the ICU specimens had produced lower void ratio values (Figure 10).

\section{DISCUSSION}

\section{I. Effect of catchment geology}

Allowing for some seasonal variability in the source waters (the test materials had been sampled at different times during the year) and minor differences in the chemical treatments at the municipal works (Table 2), the three alum WTRs were found to have broadly similar physical, shear strength and compaction behaviour despite significant differences in catchment geology. These similarities are most likely due to the fact that the engineering behaviour is dominated by the high organic content ( $\mathrm{LOI}=41-57 \%)$.

\subsection{Effects of chemical additives on shear strength and compressibility}

Low concentrations of alum and polyelectrolyte are added to the source waters at the treatment works in order to encourage 


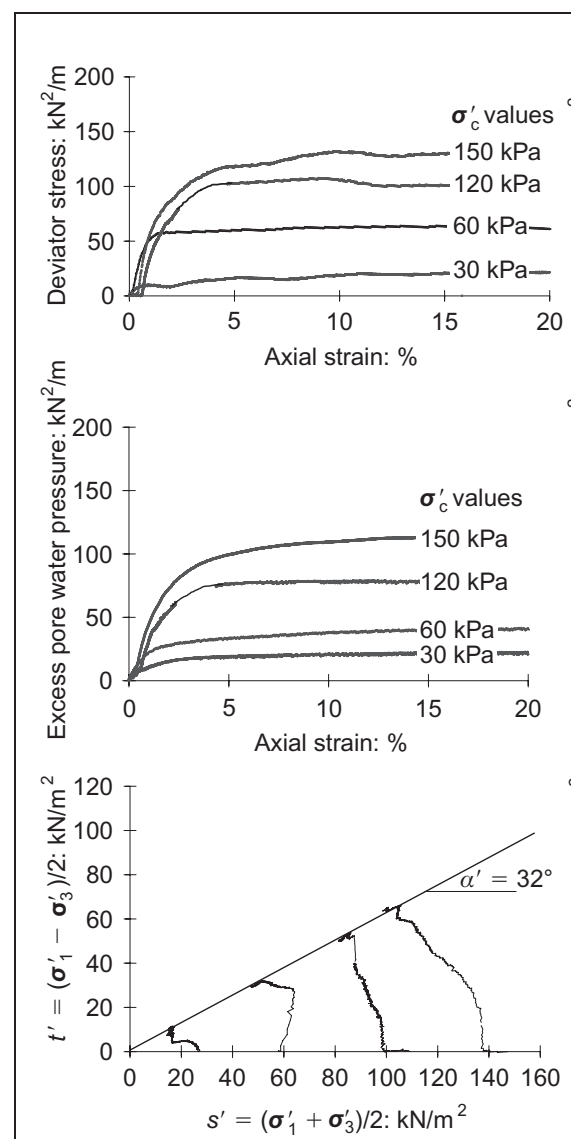

(a)
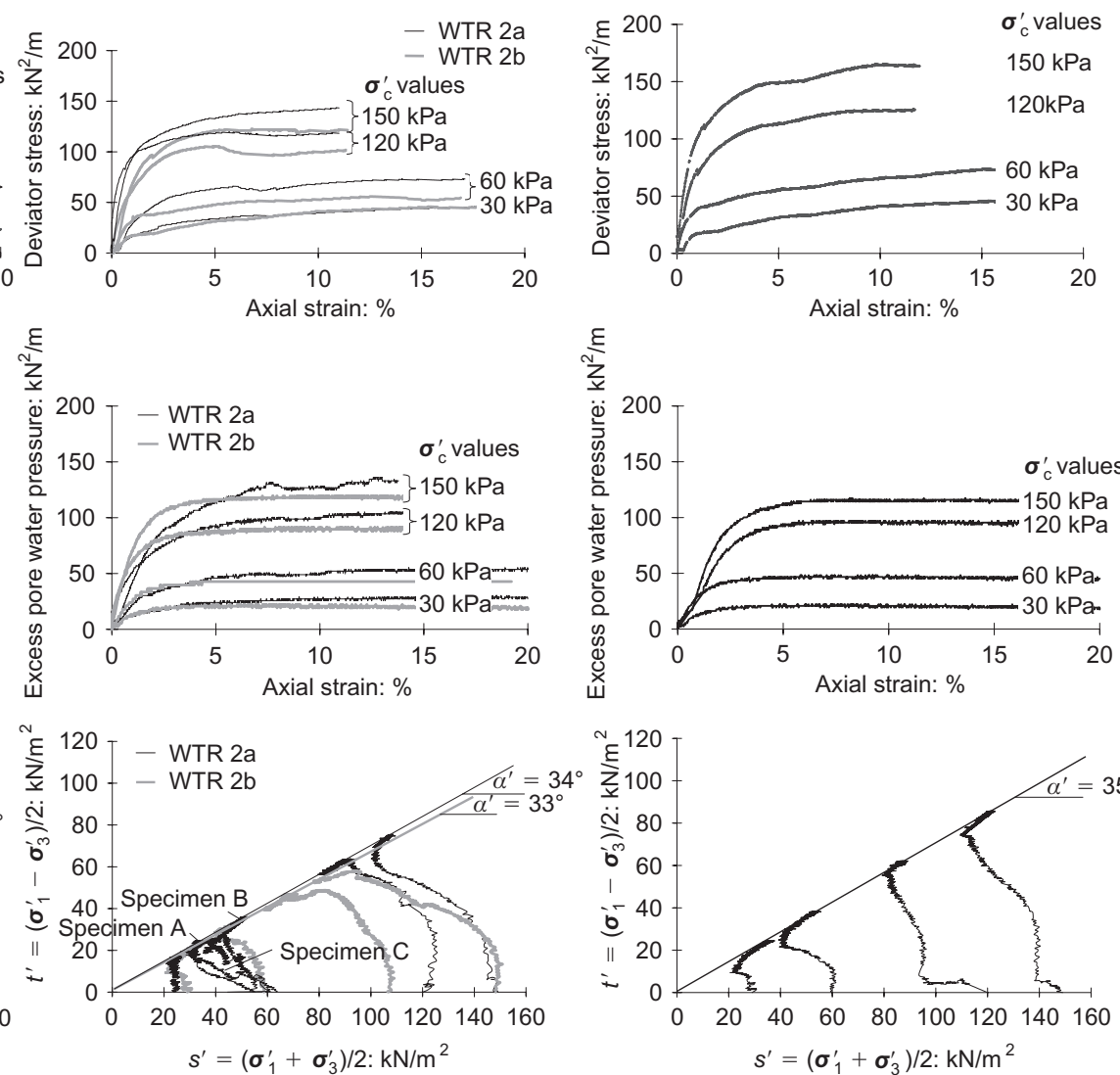

(b)

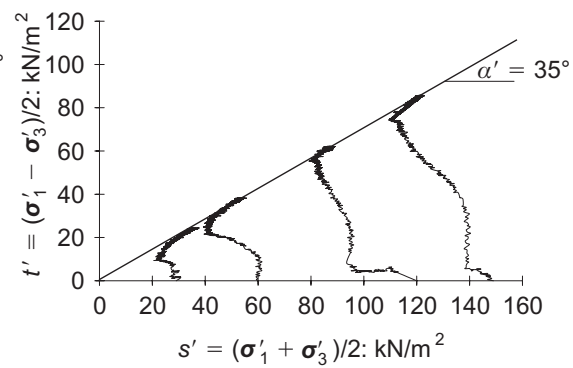

(c)

Figure 9. Stress path data: (a) WTR I; (b) WTR 2a and WTR 2b; (c) WTR 3

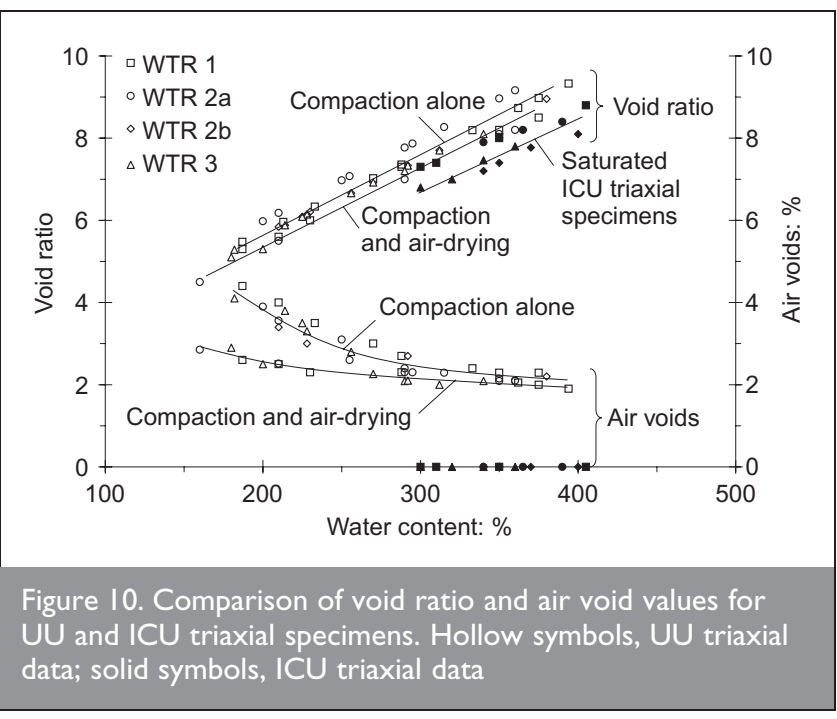

coagulation of the colloidal particles into flocs that settle out more readily under gravity. The chemical dosages that had been added at the three municipal works in this study were broadly similar, and at the higher end of the range normally used in practice, since the source waters were all medium-high in turbidity. Relatively large amounts of pore water become trapped and absorbed within the intricate matrix of colloidal particles, aluminium hydroxide precipitates and long-chained polyelectrolyte molecules that constitute the residue flocs (O'Kelly, 2008b; 0'Kelly and Quille, 2009; Wang and Tseng, 1993). These chemical additives also have the effect of increasing the inherent shear strength of the newly formed flocs (Chih Chao et al., 1997; Turchiuli and Fargues, 2004).

In general, the shear strength of the chemically coagulated residue was 10-20\% greater than that measured for the nonchemically treated residue at similar water contents. For example, Figure 11 shows the ratio of the undrained shear strength values determined from triaxial compression tests on the chemically and non-chemically treated residues from the Clareville works (WTR 2a and WTR $2 \mathrm{~b}$ respectively). The polyelectrolyte that had been added to WTR 2a aggregates and binds the colloidal solids to form floc clusters, and it is

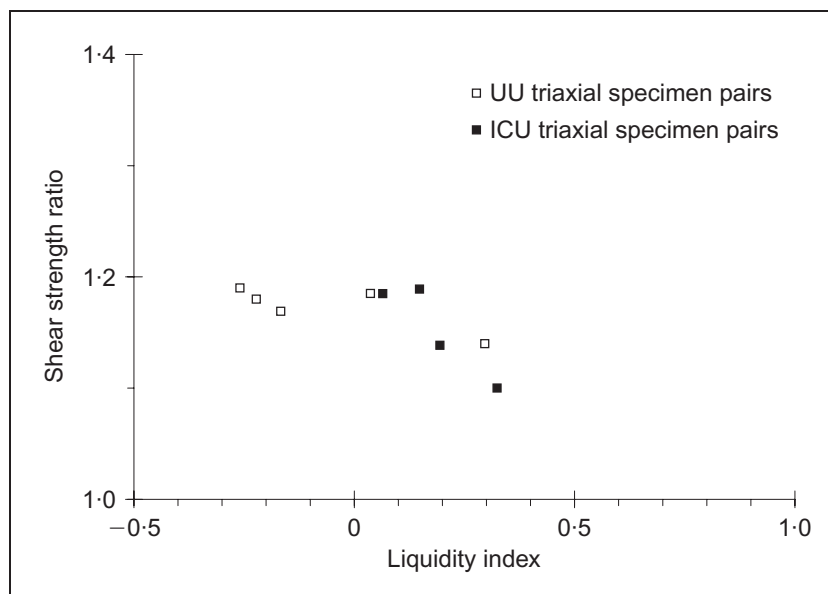

Figure II. Shear strength ratio of chemically to non-chemically treated residues from Clareville works 
postulated that the increase in bulk shear strength was due to greater interparticle contact and an increase in suction brought about by a reduction in the size of the pore voids and capillary channels. Stiffer responses and deviator stress values of up to 18\% greater were also measured for WTR 2a compared with WTR $2 \mathrm{~b}$ during ICU triaxial compression tests on specimen pairs having similar water contents (Figure 9(b)). Consequently, the effective angle of shearing resistance for the chemically treated residue was also slightly greater than that measured for the non-chemically treated residue $\left(\phi^{\prime}=42^{\circ}\right.$ and $40^{\circ}$ for WTR $2 \mathrm{a}$ and WTR $2 \mathrm{~b}$ respectively). Hence this study indicates that the shear strength and stiffness responses of high organic content slurry residues and ultra-soft soils may be increased within relatively short time periods following the addition of low concentrations of polyelectrolytes and coagulants such as alum (and potentially salts of other polyvalent cations, including calcium and magnesium).

Although the chemical additives are necessary for the efficient operation of the municipal treatment processes, they also have a downside in that the by-product residues are more difficult to dewater (thereby increasing handling, transportation and storage costs), and hence the greater bulk volume consolidates to a greater extent (producing more leachate volume) and settles over a longer time period in a sludge lagoon or monofill. For example, the chemically treated WTR 2a was less compressible and consolidated more slowly (reflected by the lower coefficient of primary consolidation values in Figure 8) than the non-chemically treated WTR $2 b$. Hence this study also indicates that the hydraulic conductivity of high organic content slurry residues may be reduced by the introduction of low concentrations of polyelectrolytes and coagulants, which could have significant potential in practice - for example in reducing the risks associated with the leachability of contaminated sediments.

Note that it is technically feasible to recover the alum from the slurry residues by chemical means, with recovery techniques having been reported since 1960 (Moran and Charles, 1960), and proprietary full-scale treatment systems are currently being developed in practice. For example, the aluminium hydroxide precipitate that forms during the coagulation process readily dissolves in a highly acidic solution within a retention tank (Xu et al., 2009); the liquid alum can be decanted, and crystallised by evaporation. Coagulant recovery is most successfully carried out using sulphuric acid (Abodo et $a l ., 1993)$ over the range of $\mathrm{pH} \mathrm{2-3}$ and for retention periods of 10-20 min. However, the effectiveness of these recovery techniques has been varied to date, with the purity of the recovered coagulant and the overall economy of these systems remaining controversial issues. Nevertheless, alum recovery would subsequently lead to greater levels of mechanical dewatering being achieved (owing to the increase in hydraulic conductivity of the residue) and hence more efficient landfill disposal. Further studies are necessary to determine the effect of coagulant recovery on the interparticle forces and structure of the residue flocs, and the likely shear strength reduction.

\subsection{Residue dewatering and landfill disposal}

The slurry residue must be adequately dewatered at the treatment works in order to reduce transportation and landfilldisposal costs, and to achieve an adequate shear strength for efficient handling, trafficability and geotechnical stability of the landfill slopes. Dewatering is achieved by mechanical and/ or thermal means, or by allowing the slurry to air-dry naturally in shallow beds (Table 5), depending on the size of the treatment works.

Current EU directives (Council of European Union Landfill and Waste Management Directives 1999, 2006) specify a maximum water content of 300\% for municipal landfilling of sludge and residues. The landfill operator usually measures the water content value by oven-drying representative test specimens before accepting the residue on site. However, no universal relationship exists for soils between the water content and undrained shear strength, which is used to calculate the shortterm factor of safety against geotechnical instability, since the shear strength is also dependent on a range of other factors, including natural differences in the composition of the suspended solids in the source water (effects mineralogy and organic content), the different types of treatments and amounts of chemicals used to separate the residue by-product at the municipal works, the test method, and the degree of specimen saturation. For example, a review of the literature (Novak and Calkins, 1975; Wang et al., 1992; Wichmann and Riehl, 1997) indicates that, at 300\% water content, the undrained shear strength of alum WTRs can range between 6 and $80 \mathrm{kPa}$ (Figure 12), although the amounts of chemicals in the residues tested by other researchers were not reported. However, the measured undrained shear strengths of the three alum WTRs tested in this study were more consistent $\left(\boldsymbol{s}_{\mathrm{u}}=40-80 \mathrm{kPa}\right.$ ), since the source waters, treatment processes and amounts of chemical additives were comparable.

Minimum shear strengths of 20 and $25 \mathrm{kPa}$ were recommended by Loll (1991) and Siedlungsabfall (1993) for the co-disposal of slurry and residues with municipal waste at landfills. The wet residues are placed in thin layers and mixed and scarified in situ with municipal waste, which has the effect of reducing the water content (Spinosa, 2004) and thereby increasing the shear strength of the residue fraction. An undrained shear strength of at least $20 \mathrm{kPa}$ was achieved at 340\% water content for the three alum WTRs tested in this study, although for other WTRs and sewage sludges the shear strength may be significantly less than $20 \mathrm{kPa}$ at 300\% water content (Figures 1 and 12). Higher undrained shear strengths of typically $50 \mathrm{kPa}$ are recommended for geotechnical stability in the case of WTR monofills. Hence it would be more prudent for landfill operators to specify a minimum undrained shear strength value based on sound geotechnical considerations, rather than the current requirement for a maximum of 300\% water content alone, in determining the acceptability of sludge and residues for landfill disposal.

\begin{tabular}{|lc|}
\hline Method & Water content: \% \\
\hline Centrifuge & $455-900$ \\
Belt press & $400-570$ \\
Belt dryer & $350-500$ \\
Recessed-plate filter press & $235-400$ \\
Lagoon & $150-570$ \\
Drying bed & $70-230$ \\
& \\
Table 5. Water contents achieved by different dewatering \\
methods (Metcalf and Eddy, 2003) \\
\hline
\end{tabular}




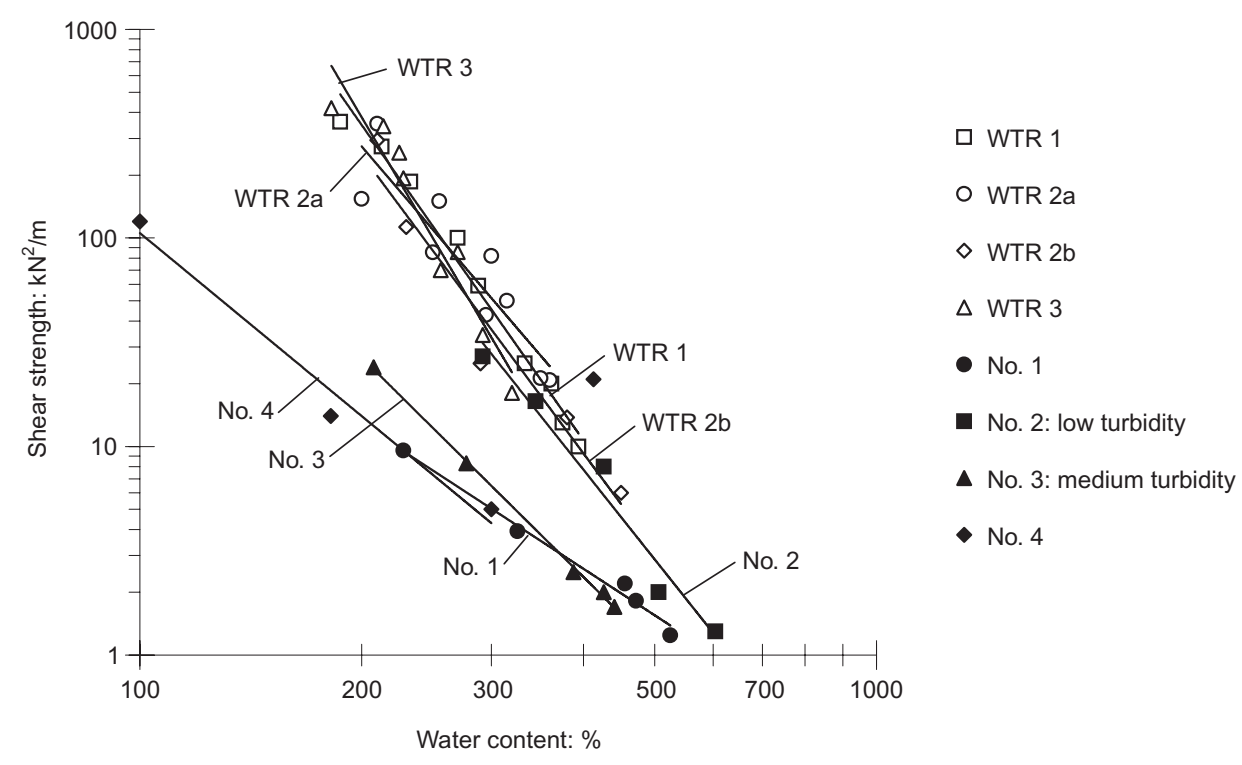

Figure 12. Undrained shear strength against water content data for alum WTRs. No. I, Novak and Calkins (1975); No. 2 and 3, Wang et al. (1992); No. 4, Wichmann and Riehl (1997)

The laboratory vane apparatus provides a quick and accurate method of measuring the undrained shear strength (0'Kelly, 2004; Wichmann and Riehl, 1997) in order to assess whether the residue has been adequately dewatered before leaving the treatment works and again by the landfill operator before accepting the residue for disposal. Data for undrained shear strength against water content, such as those shown in Figure 12, can be used as part of the selection process for an appropriate dewatering system for the slurry residue specific to a particular treatment works in order to achieve a specified minimum undrained shear strength. For example, water content values of $340 \%$ and $250 \%$, which correspond to undrained shear strengths of at least 20 and $50 \mathrm{kPa}$ respectively, for the alum WTRs tested in this study can be achieved using the recessed-plate filter press device and also possibly using a belt-dryer device (Table 5). The belt dryer mechanically dewaters the slurry residue under an applied stress of $800-1000 \mathrm{kPa}$, followed by full or partial drying of the residue cake at low temperatures. In general, the belt press device alone cannot reduce the water content sufficiently to satisfy geotechnical stability criteria for landfill disposal. Alternatively, thermal treatment or soil-conditioning techniques may be used to dewater the wet residues sufficiently and expeditiously.

Finally, standard Proctor compaction effort resulted in some overcompaction of the alum WTRs tested in this study (as reflected by some swelling of the compacted specimens). Hence a lighter compactive energy of about one-third standard Proctor compaction effort should be used for field compaction, following the recommendations of Loll (1991) and O'Kelly (2004).

\section{CONCLUSION}

Alum WTRs are high-plasticity organic clays. Despite significant differences in catchment geology, and allowing for some seasonal variability in the medium-high turbidity source waters and minor differences in the chemical treatments at the municipal works, the three alum WTRs tested in this study generally had similar engineering properties, because the behaviour was dominated by the high organic content. The residues derived from the two peaty catchments (i.e. peat over granite bedrock and limestone bedrock) were found to have slightly higher undrained shear strengths than the residue derived from a limestone-bedrock catchment, over the water content range tested.

The slurry residues had low bulk and dry densities, and were highly compressible, although the consolidation rate was low $\left(c_{\mathrm{vi}}=0 \cdot 08-0 \cdot 25 \mathrm{~m}^{2} /\right.$ year for $\boldsymbol{\sigma}_{\mathrm{v}}^{\prime}=30-150 \mathrm{kPa}$, where $c_{\mathrm{vi}}$ is the coefficient of consolidation for isotropic conditions).

Wet alum WTR underwent significant thixotropic hardening (e.g. a strength gain ratio of $3 \cdot 3$ measured for specimens cured at constant composition marginally below the liquid limit). The plastic limit represents a lower bound for thixotropic behaviour. The dewatered residues had high values of effective angle of shearing resistance of $39-44^{\circ}$, and a mean undrained shear strength to effective confining pressure ratio of $1 \cdot 8$. Although higher shearing rates produced a higher stress-strain modulus for fresh identical specimens, the measured undrained shear strengths were similar, indicating that undrained creep effects were not significant.

The low concentrations of polyelectrolyte in the residues significantly enhanced the shear strength and stiffness responses, by binding the constituent flocs together to form floc clusters and producing an increase in suction due to reductions in size of the pore voids/capillary channels and deactivation of some pore water.

The undrained shear strength was 10-20\% greater and the effective angle of shearing resistance was also slightly greater for the alum WTR than for the non-chemically treated residue. Alum WTR also had a more elastic perfectly plastic constitutive response compared with that generally associated with highplasticity organic clay, with specimen failure typically occurring between $2 \%$ and $10 \%$ axial compressive strain. 
Standard Proctor compaction of the mechanically dewatered WTRs produced low bulk and dry densities of 1.13-0.96 and $0 \cdot 21-0 \cdot 36 \mathrm{t} / \mathrm{m}^{3}$ respectively, over the reducing water content range of 400-200\%. A lighter compactive energy of about one-third standard Proctor compaction effort is recommended for field compaction.

From the literature, at the maximum water content value of 300\% specified by current EU directives for municipal landfilling of sludge and residues, the shear strength of alum WTRs can range from 6 to $80 \mathrm{kPa}$ (for alum WTRs tested in this study, $\boldsymbol{s}_{\mathrm{u}}=40-80 \mathrm{kPa}$ ). Hence it would be more prudent for landfill operators to specify a minimum undrained shear strength value based on sound geotechnical considerations (e.g. for the co-disposal of residues at municipal landfills, $\boldsymbol{s}_{\mathrm{u}}=20 \mathrm{kPa}$ minimum) rather than the current requirement of a maximum $300 \%$ water content.

The recessed-plate filter press and belt-dryer devices can dewater the slurry residue sufficiently at the treatment works in order to achieve the minimum recommended shear strength values of 20 and $50 \mathrm{kPa}$ (target water contents below 340\% and 250\%) for the efficient disposal of WTRs in municipal landfills and monofills respectively. Alternatively, thermal treatment or soil-conditioning techniques may be used.

Although the chemical additives are necessary for the efficient operation of the municipal treatment processes, they also have a downside in that the by-product slurry residue is more difficult to dewater and consolidate than the non-chemically treated residue. The recovery of the alum from the slurry residue, which can be achieved by chemical means, would subsequently lead to greater levels of mechanical dewatering and hence more efficient disposal/reduced landfill costs.

\section{ACKNOWLEDGEMENTS}

The authors would like to thank Martin Carney, Mbakure Johnson and Patrick Fogarty for carrying out some of the tests on the WTRs at the geotechnical laboratories, Trinity College Dublin. Michael Quille would also like to acknowledge funding received through postgraduate research awards from Trinity College Dublin and the Geotechnical Trust Fund of Engineers Ireland.

\section{REFERENCES}

Abodo MSE, Ewida KT and Youssef YM (1993) Recovery of alum from waste sludge produced from water treatment plants. Environmental Science Health 28(6): 1205-1216.

Bell FG (2000) Engineering Properties of Soils and Rocks, 4th edn. Wiley-Blackwell, New York.

BSI (British Standards Institution) (1990a) BS 1377 Methods of Test for Soils for Civil Engineering Purposes. BSI, Milton Keynes.

BSI (British Standards Institution) (1990b) BS 1377: Part 7 Methods of Test for Soils for Civil Engineering Purposes. Shear Strength Tests (Total Stress) BSI, Milton Keynes.

BSI (British Standards Institution) (1990c) BS 1377: Part 8 Methods of Test for Soils for Civil Engineering Purposes. Shear Strength Tests (Effective Stress). BSI, Milton Keynes.

Chih Chao W, Chihpin H and Lee, DJ (1997) Effects of polymer dosage on alum sludge dewatering characteristics and physical properties. Colloids and Surfaces A:

Physicochemical and Engineering Aspects 122(13): 89-96.
European Parliament and Council of the European Union (1998) Council Directive 1998/83/EC of 3rd November 1998 on the quality of water intended for human consumption. Official Journal of the European Communities, L330, 32-54.

European Parliament and Council of the European Union (1999) Council Directive 1999/31/EC of 26th April 1999 on the landfill of waste. Official Journal of the European Communities, L182, 1-19.

European Parliament and Council of the European Union (2006) Directive 2006/12/EC of the European Parliament and of the Council of 5th April 2006 on waste. Official Journal of the European Communities, L114, 1-13.

Geuzens P and Dieltjens W (1991) Mechanical strength determination of cohesive sludges: a Belgian research project on sludge consistency. In Recent Developments in Sewage Sludge Processing (Colin F, Newman PJ and Puolanne YJ (eds)). Elsevier, London, pp. 14-23.

Lim S, Jeon W, Lee J, Lee K and Kim N (2002) Engineering properties of water/wastewater-treatment sludge modified by hydrated lime, fly ash and loess. Water Research 36(17): 4177-4184.

Loll U (1991) Measurement of laboratory vane shear strength as community standard or reference method for testing the suitability of dewatered sludges for use as landfill. In Treatment and Use of Sewage Sludge and Liquid Agricultural Wastes (L'Hermite P (ed.)). Elsevier, London, pp. 310-315.

Metcalf \& Eddy, Inc (2003) Wastewater Engineering, Treatment and Reuse, 4th edn. McGraw-Hill, New York.

Mitchell JK and Soga K. (2005) Fundamentals of Soil Behavior, 3rd edn. Wiley, Hoboken, NJ.

Moran RJ and Charles PR (1960) Recovery and reuse of alum sludge at Tampa. American Water Works 52(7): 857-866.

Novak JT and Calkins DC (1975) Sludge dewatering and its physical properties. Journal of the American Water Works Association 67(1): 42-45.

O'Kelly BC (2004) Geotechnical aspects of sewage sludge monofills. Proceedings of the Institution of Civil Engineers, Municipal Engineer 157(3): 193-197.

0'Kelly BC (2005a) Consolidation properties of a dewatered municipal sewage sludge. Canadian Geotechnical Journal 42(5): $1350-1358$.

0'Kelly BC (2005b) Mechanical properties of dewatered sewage sludge. Waste Management 25(1): 47-52.

0'Kelly BC (2005c) Sewage sludge to landfill: some pertinent engineering properties. Journal of the Air and Waste Management Association 55(6): 765-771.

O'Kelly BC (2006) Geotechnical properties of municipal sewage sludge. Geotechnical and Geological Engineering 24(4): $833-$ 850.

0'Kelly BC (2008a) Development of a large consolidometerpermeameter apparatus for testing soft soils. Proceedings of the ASCE GeoCongress on the Challenge of Sustainability in the Geoenvironment, New Orleans, 5: 60-67.

0'Kelly BC (2008b) Geotechnical properties of a municipal water treatment sludge incorporating a coagulant. Canadian Geotechnical Journal 45(5): 715-725.

O'Kelly BC (2009) Development of a large consolidometer apparatus for testing peat and other highly organic soils. SUO-Mires and Peat, Finnish Peatland Society 60(1-2): 23-36.

O’Kelly BC and Quille ME (2009) Compressibility and 
consolidation of water treatment residues. Proceedings of the Institution of Civil Engineers, Waste and Resource

Management 162(2): 85-97.

Raghu D and Hsieh H-N (1986) Material properties of water treatment plant sludges. Civil Engineering for Practising and Design Engineers 5(11-12): 927-941.

Roque AJ and Carvalho M (2006) Possibility of using the drinking water sludge as geotechnical material. Proceedings of the 5th International Congress on Environmental Engineering, Cardiff 2: 1535-1542.

Seed HB and Chan CK (1959) Structure and strength characteristics of compacted clay. ASCE Journal of Soil Mechanics and Foundations Division 85: 87-128.

Siedlungsabfall TA (1993) Dritte allgemeine Verwaltungsvorschrift zum Abfallgesetz. Bundesanzeiger, Munich.

Spinosa L (2004) EU strategy and practice for sludge utilization in agriculture, disposal and landfilling. Residuals Science and Technology 1(1): 7-14.
Turchiuli C and Fargues C (2004) Influence of structural properties of alum and ferric flocs on sludge dewaterability. Chemical Engineering 103(1-3): 123-131.

Twort AC, Ratnayaka DD and Brandt MJ (2000) Water Supply, 5th edn. Arnold, London.

Wang MC and Tseng W (1993) Permeability behavior of a water treatment sludge. ASCE Journal of Geotechnical Engineering 119(10): 1672-1677.

Wang MC, Hull JQ, Jao M, Dempsey BA and Cornwell DA (1992) Engineering behavior of water treatment sludge. ASCE Journal of Environmental Engineering 118(6): 848864.

Wichmann K and Riehl A (1997) Mechanical properties of waterwork sludges: shear strength. Water Science and Technology 36(11): 43-50.

Xu GR, Yan ZC, Wang YC and Wang N (2009) Recycle of alum recovered from water treatment sludge in chemically enhanced primary treatment. Hazardous Materials 161(2-3): $663-669$.

\section{What do you think?}

To discuss this paper, please email up to 500 words to the editor at journals@ice.org.uk. Your contribution will be forwarded to the author(s) for a reply and, if considered appropriate by the editorial panel, will be published as discussion in a future issue of the journal.

Proceedings journals rely entirely on contributions sent in by civil engineering professionals, academics and students. Papers should be 2000-5000 words long (briefing papers should be 1000-2000 words long), with adequate illustrations and references. You can submit your paper online via www.icevirtuallibrary.com/content/journals, where you will also find detailed author guidelines. 